\title{
Inside the outback: An exploration of domesticated landscapes in Semco's Long Stitch Originals series of the 1980s
}

\author{
Sera Waters
}

\begin{abstract}
In 1983, Semco, a company with an established market for fine embroidery patterns and kits, released a new series titled 'Long Stitch Originals'. This series differed from the company's previous linen patterns and kits for its use of wool, the non-utilitarian and decorative role of the completed item, and the series' depiction of Australian landscapes rather than British motifs of domesticity. This essay argues that these kits invoked strategies that were used in the early twentieth-century landscape tradition and, in doing so, engendered a domestic and visual form of nationalism that was prevalent in the lead up to Australia's bicentenary. Though these kits are not part of institutional collections and have been largely removed from Australian homes, an examination of them uncovers a popularised visual form of settler colonialism of the 1980s. Their material and pictorial use of abstraction, idealisation and patterning will be explored as nostalgic renditions of the Australian landscape; a looking backward in the face of the realisations wrought by postcolonialism.
\end{abstract}

In September 1983, Semco Pty Ltd began its release of 'original designs' for a new series of needlework kits called Long Stitch Originals ('Long stitch means a fast finish' 1986). These kits were available in department stores and consisted of a tapestry needle, dyed Australian wool, basic instructions, and an interlock canvas printed with the black outline of an 'Australian' design (Figures 1 and 2). Once completed, the round scene, 29 centimetres in diameter, could be displayed in a mount and frame, which was also produced by Semco, thereby fulfilling its design as decoration for the home. While Semco was not alone in supplying imported needlecraft kits to the Australian market, they were leaders in manufacturing needlecraft supplies onshore and creating Australian designs (Dexter 1973). Throughout the 1980s, the Long Stitch Originals series expanded into a range advertised in the Age as 'traditional Australian outback scenes' ('Long stitch' 1986). Rather than 'outback', however, the long stitches considered in this essay (which are restricted to the series' first issue of kits, 
numbered approximately 3071 to $3104^{1}$ ), overwhelmingly represented pastoral scenes, predominantly homesteads in idealised rural settings, with a number of exceptions such as a paddle steamer (Figure 3), Captain Cook's relocated house, ${ }^{2}$ or cut flowers. As will be explored, this misuse of the Australianism 'outback' is typical of the generalising, idealising and propagandising that was applied to popularised versions of Australian landscapes during the twentieth century. When unpicked, this long stitch series can be read materially and pictorially as domesticated examples of the way Australian landscapes housed the nationalistic agendas that were set against the late twentieth century's rising tide of postcolonial awareness.

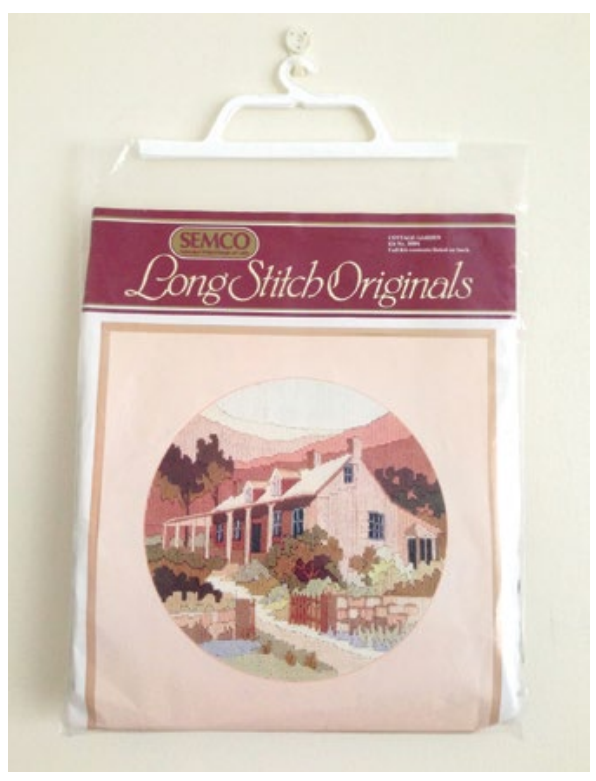

Figure 1. Semco Long Stitch Originals series, 'Cottage garden', kit no. 3094 (front)

Photo: Sera Waters

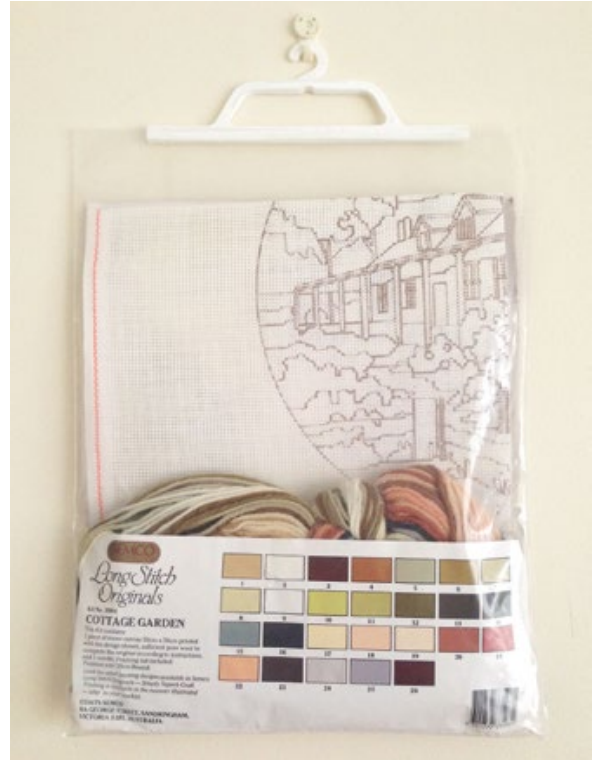

Figure 2. Semco Long Stitch Originals series, 'Cottage garden', kit no. 3094 (back)

Photo: Sera Waters

1 Despite its popularity and ubiquity, I have been unable to ascertain how many long stitches were released for this series. According to Ruth Lee, whose dissertation explores Semco pattern production from 1910-60, the company kept few, if any, records of its products. She writes 'the patterns, as far as I could ascertain, were never copyrighted ... only the name was patented. (This has made dating of the patterns difficult as no accurate records appear to have been kept)' (1993: 136). This is also true of the Long Stitch Originals series. I have found (as second-hand products) patterns ranging from 3071-3104, which indicates that there are at least 33 in this series. It is likely, however, that there were many more, given the 1979 crewel series, a precursor to the Long Stitch Originals, occupy the 1200s, and an extension of the Long Stitch Originals series, which was also released in the 1980 s (but with many more historical houses, flora and fauna subjects) take up numbers spanning approximately 3300-0002 to around 3301-0012. The first issue of this series differs from the extension of the series, which incorporated embroidery threads for finer details, and which took up more flora and fauna, as well as historic houses as subject matter.

2 Kit no. 3081 is an image of Captain James Cook's cottage: 'the Victorian house ... was built in Yorkshire in 1755 by the parents of Captain James Cook ... [and] was transported to Melbourne and erected in the Fitzroy Gardens in 1934. The cottage was taken apart brick by brick and packed into cases and barrels to be shipped to Australia, along with cuttings of ivy that originally adorned the house, which were replanted when the building was erected in Melbourne' ('Cooks' cottage' 2013). 
In Australia, Semco's Long Stitch Originals series arose from a century-long lineage of needlecraft production. Originally founded in 1908 as a Melbournebased importation company, ${ }^{3}$ Semco Pty Ltd was transformed in $1915^{4}$ to begin manufacturing 'women's apparel, whitework and transfer patterns' under the new leadership and business vision of Charles Henry Mylius (Lee 1993: 135). In 1924, the growing company relocated to Black Rock, Victoria, and there produced an extended range of 'traced art needlework, paper transfers and handicraft instruction booklets' (Lee 1993: 135). Many of their popular sellers included domestic utilitarian linens (such as aprons and doilies) ${ }^{5}$ printed with 'pretty' and predominantly British motifs to be embroidered with a range of fine cotton stitches, including French knots, feather stitch and stem stitch. From 1915 until the 1970s, Semco was secure in its position as a successful Australian producer and distributor of fancywork supplies and kits. ${ }^{6}$ By 1973 , they supplied and decorated Australian homes with a range of more than 600 products, including many popular linen napery ranges. Overall, there were over 10,000 Semco products available (Dexter 1973).

The developments in Semco's handicraft and booklet production in these early years appear to have arisen from Mylius's business foresight into an Australian market. English imported needlework articles and booklets were popular in Australia from the 1890s (Fletcher 1989: 18), and Mylius undertook research in England in the early 1920s (Lee 1993: 135), where it is likely that he observed textile technologies such as mechanised dyeing and printing processes, as well as the late Victorian development of instructional language. The addition of more detailed written and diagrammatical instructions addressed gaps in needlework patterns that, prior to this time, gave 'no indication of the kinds of stitches, colors, or materials to use to reproduce the patterns in needle or thread' (Daly Goggin 2002: 326). Scant instructions assumed a high level of needlework knowledge and creative authorship in customers, whereas Semco's use of increasingly instructional communication with their consumers reflects

31908 is a date provided by Lee (1993: 135) who records that initially Semco was Stanley E. Mullen Company, which imported products such as sheet music, postcards and transfers. Her information is obtained from an unpublished paper written by a former Semco director, Alec Murray, in 1990. I have discovered some disparity around the date this company was founded. Nancy Dexter (1973) contradicts the founding year of 1908 and claims that it began in 1904. A Brandcorp (the name Semco Company has gone under since 2009) summary also diverges in dating the company's foundation to 1907: 'Samuel E. Mullins [sic] founded the Semco Company in 1907, specializing in Embroidery products ... [and] was the 3rd company incorporated in Victoria'. ('BrandcorpInnovative world class brands' 2009).

4 Marion Fletcher presents an alternative date of 1935 for the change of the company's name to Semco (1998: 18). The first three letters of Semco were derived by Mylius from the name of the company's founder S.E. Mullen (Gamble 2013).

5 Lee describes this range as: 'small d'oyleys and tray cloths, piano runners, children's clothes, tea towels, peg bags, table cloths, place mats, cushions, handkerchiefs and the ubiquitous calico apron' (1993: 141).

6 On their promotional webpage, Brandcorp claim '.... even 100 years ago the Semco brand was a leader in its market segment. Semco had uninterrupted business through two world wars and the Great Depression, providing Australia and New Zealand with beautiful Needlework, Haberdashery and Craft products. Semco still manufactures many of its needlecraft products in its facilities in Sydney' ('Brandcorp' 2009). This claim has been substantiated by Lee's dissertation, which records the popularity of Semco amongst her interviewees (1993); a survey conducted by Semco in the 1970s which found that 80 per cent of Australian women were familiar with the brand (Dexter 1973); and the 'Semco of Black Rock' article, which charts the Australian history of Semco history throughout the twentieth century (Gamble 2013). 
an acceptance that technical needlework skills were declining in the general population, as they had been since the Industrial Revolution (Fletcher 1989: 9). With profits in mind, it was by not presupposing extensive needlecraft knowledge, coupled with technological advances in mass-producing textile kits, which enabled the distribution of Semco's textile products to a broadening market at an affordable price. With the release of the Long Stitch Originals series 60 years later, both production techniques and instructions had advanced to accommodate a growing population of amateur consumers.

Mylius's uptake of textile advances in Australia were focused on extending the Semco business towards manufacturing products locally. In line with the social politics of the era, however, the growing business also expanded the use of a visual language that 'reflected and reinforced the domestic world of the Anglosaxon housewife' (Lee 1993: 140). Texts that record individual voices from Semco are lamentably scarce, so it is significant that Lee's study draws from unpublished papers and interviews with past employees, many of whom are now deceased. Extracts from her interviews reveal a structure within Semco that upheld an 'ideology of domesticity' by restricting selected motifs to those 'without links to time or the outside world' (1993: 140, 141). The sometimes daring vision of the six women designers who developed Semco's patterns was regulated by an overwhelmingly male hierarchy of management and travelling salespeople who made decisions based on their perceptions and knowledge of consumer demand. Diana, a retired head designer from Semco, stated in interview with Lee:

Designers had to submit 20 or 30 or 40 designs and take them down to the big chief and the travellers and everyone had a look at them and decide which six they were going to have. They never chose the ones we liked you know ... but still they were selling them I suppose and they knew ... what they thought they would sell. They didn't always know. (1993: 136)

As a result, an English Rose motif, design SM11, was repeatedly reinvented and remained in circulation for many decades (Lee 1993: 140). Some Australian flora and motifs found a place in Semco's designs from the beginning, ${ }^{7}$ but mainly it was 'pretty' British motifs that populated designs prior to the Second World War. In summary Lee writes:

... the world depicted by the motifs of the linen embroideries of 1920-50 is domestic ... timeless ... usually rural and British ... where houses and gardens feature. It is a static world and intensely feminine, reflecting a nostalgic view of a domestic idyll. (1993: 141)

\footnotetext{
7 Jennifer Isaacs dedicates two pages in her volume The Gentle Arts: 200 Years of Australian Women's Domestic \& Decorative Arts, to 'Semco commemorative embroideries', which show aprons, quilts, as well as crochet, embroidered with designs that celebrate local events such as Amy Johnson's 1930 flight from England to Australia in a gypsy moth biplane, the opening of the Sydney Harbour Bridge, or the cricketing milestones of Don Bradman (1987: 194-95). These embroideries, which are far less common than the British-inspired designs, have been collected by Australian institutions, such as the Powerhouse Museum in Sydney.
} 
This British-derived 'ideology of domesticity' was reiterated by Semco in Australia until the 1950s and represents a culture-wide predilection that certainly was not limited to this company. Lee makes the point that Semco did not dictate trends to their buying public, theirs 'was an essentially conservative enterprise' responding to perceived consumer demand (1993: 135). It is necessary, however, to acknowledge that Semco's process of purposeful selection not only had the potential to perpetuate gender divisions but effectually excluded specific demographics; for example, needleworking men and people of diverse cultural backgrounds. Just as significant, though, was an unresponsiveness towards the genuine interest of many Australian women in subjects beyond British domesticity. In 1949, Country Women's Association of Australia (CWA) member Mrs E.A. Coghlan, reflected:

\footnotetext{
... it was a pity that Australian artists did not publish a book featuring truly Australian designs taken from Aboriginal drawings or wild flowers. Such a book would be a great assistance to country women who at present were able to copy only standard English designs in their handicraft (Eagle 2001: 8).
}

Despite the problematic nature of such cultural appropriation, at its core this statement reflects a yearning for subjects with a non-British-Australian inflection. This challenge was taken up by many artists and designers from the late nineteenth century onwards (Bogle 1998) but, for Semco, it was to happen in the latter half of the twentieth century.

From the 1950s, Semco conservatively expanded its repertoire to include some international motifs, commemorative motifs of important local events and, somewhat ironically, eventually Australian motifs such as the kangaroobut this did not happen until later (Lee 1993: 141). While a smaller number of these designs were produced than the popular British-inspired designs, their production at all suggests the postwar market of the needlework hobbyist was diversifying, and this was likely enabled by the growing migrant population as well as the opening up of the world via global telecommunication systems, including television. But popularity was still somewhat fickle. In 1941, Diana designed for Semco a motif of a Mexican lady that continued to sell into the 1950s, whereas, for unknown reasons, her South Sea Islander design was unpopular (Lee 1993: 141). Another designer, Joan, stated her 1980s historic houses and tram designs 'kind of bombed out a bit ... I thought people were interested in history, but perhaps they aren't. They want pretty-pretty things' (Lee 1993: 141). What was thought of as 'pretty-pretty' moved with fashion informed by Australian and international cultural shifts; this would also eventually be the case with the increasing, then ultimately decreasing, appeal of the Australian landscapes that feature in the Long Stitch Originals series. 


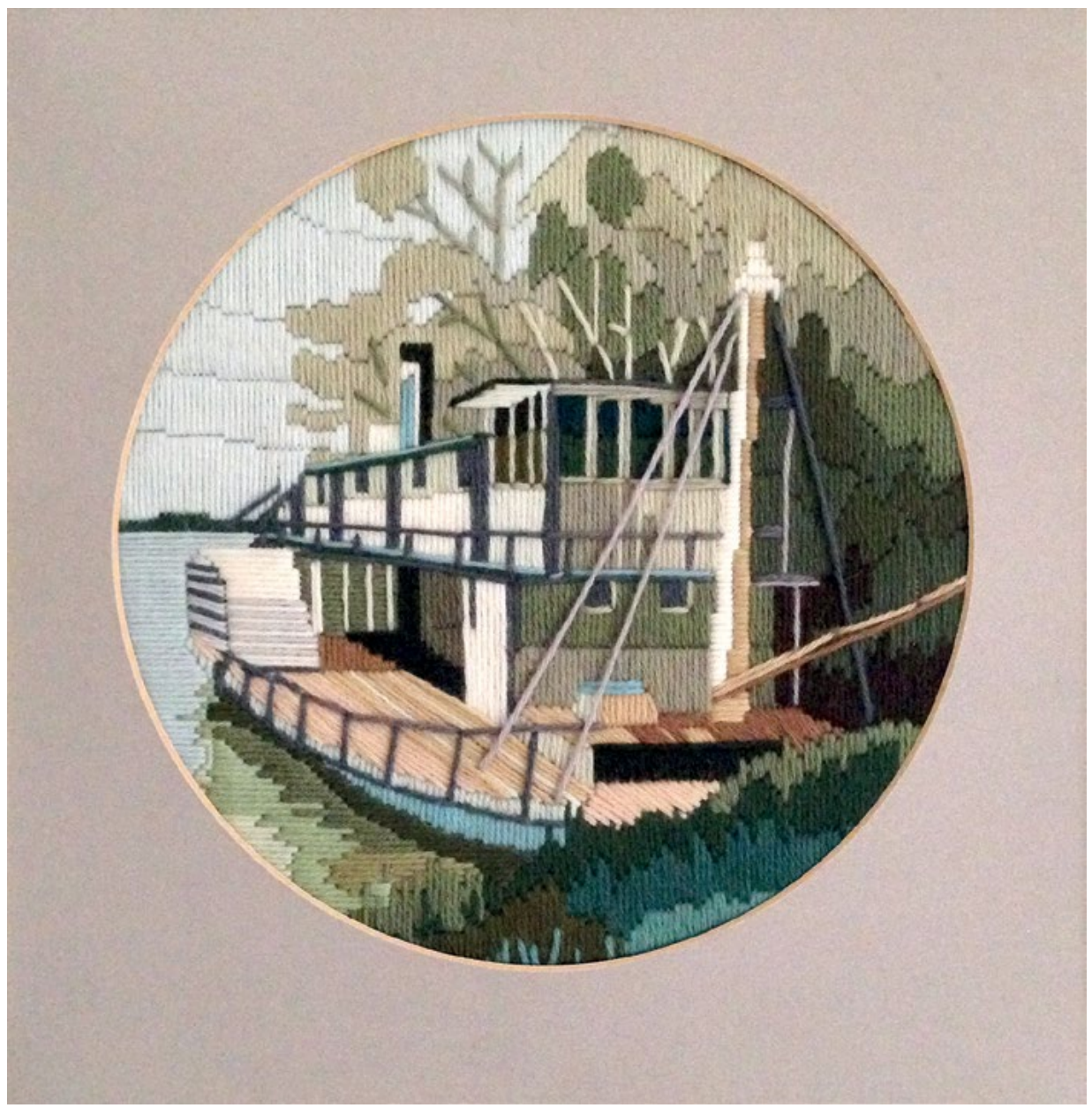

Figure 3. Maker unknown, Semco Long Stitch Originals series, 'Paddle steamer', kit no. 3088

Photo: Sera Waters

To keep up with changing fashions in the 1970s, Semco was an instigator of new textile technologies in Australia. In 1973, when Semco released a crewel series of Australian designs supplied with imported wool, Nancy Dexter reported that crewel and wool work used for upholstery and pictures was 'the fastest moving form of embroidery overseas at the moment' (1973). By 1979, Semco was under the leadership of general manager Robert McAdam ('Tapestry wool' 1979: 8). In response to this burgeoning market, the company worked with the Australian Wool Corporation to develop technologies that were capable of tapestry wool production in Australia. According to the Canberra Times, the result was 'Semco Gobelin Wool, processed by Alpha Spinning Mills and produced in 250 quality 
controlled shades in Semco's new factory' (1979: 8). ${ }^{8}$ Unlike the crewel kits, long stitch and other wool-supplied kits produced after 1979, including the Long Stitch Originals series, proudly bore the authoritative Australian Woolmark label. This proclaimed Semco's use of wool that had been farmed, processed and dyed in Australia, thereby linking their product to a successful industry that had been long regarded as a national symbol.

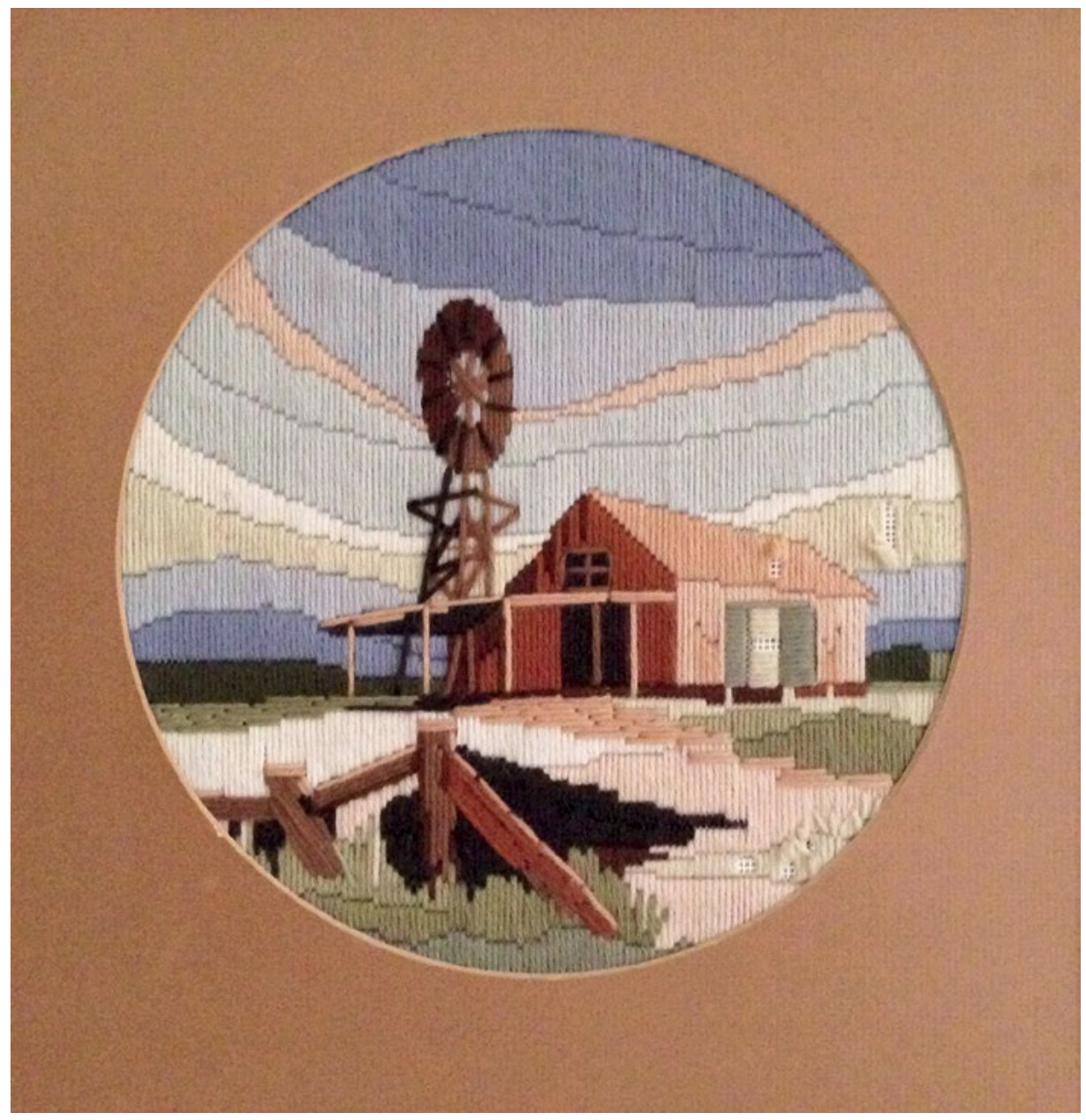

Figure 4. Maker unknown, Semco Long Stitch Originals series, title and kit no. unknown Photo: Sera Waters

8 The Black Rock premises were sold in the 1970s for a housing development and Semco's 'new factory' was once again in Melbourne ( Lee 1993: 136). 
Part of the appeal of wool, aside from its international fashion status and, onshore, its material link to 'Australia', is captured in the title of a short article in the Age: 'Long stitch means a fast finish' (1986). The use of thick strands of wool, paired with one (sometimes two) basic stitching techniques, meant the kit could be completed in ' $8-10$ hours' by individuals with near to no stitching experience ('Long stitch' 1986). This alone likely fuelled their popularity with the amateur market. ${ }^{9}$ By contrast, the prior 1973 crewel series, similarly using wool (albeit one ply), specified instructions for 20 or more stitch techniques to render a scene on a printed linen ground. Instead, the Long Stitch Originals series only required one main technique: the single long stitch, moving horizontally, vertically and sometimes diagonally in and out of a sturdy, interlock canvas ground (which was easier for amateurs to work), with an occasional French knot for floral embellishment. Working the long stitches covered extensive ground with each movement, which differed significantly to other needlecraft kits on the market that employed finer, skilled and time-consuming techniques.

The linens and finer canvases used in some kits were of a quality that could be left uncovered on completion of the project. Due to its thickness, wool requires an open weave canvas ground that needs to be entirely covered by stitches. While this requirement is not unusual for many forms of canvas work, the round design, coupled with the stiffness of the canvas and the length of the stitches, which gape when not flat, made it more difficult to repurpose the kits (as upholstery, for example). Instead the round scenes were specifically designed to fit the readily available pre-cut mount boards and frames. As well, deviations from the printed lines defining areas to be filled with the appropriate and pre-selected (and sometimes pre-sorted) wool colour, risked gaps, framing difficulties, or running out of a colour, causing the ground to be visible and or compromising the pictorial quality of the simulated landscape. Unlike Semco's printed linen patterns of the previous era, which provided basic outlines to embroider that could be extended by 'the clever ones [who] used to fill them in and put them in the Royal Show' (Diana, cited in Lee 1993: 127), these simple long stitch kits supplied a market that was becoming less technically proficient, yet imitated a style that superficially attempted to effect 'skill' via faster and less technically proficient means.

9 The Age claimed that the popularity of the Long Stitch Originals series had spawned similar models internationally ('Long stitch' 1986). Perhaps this was because Semco had been taken over by Scottish Company Coats in 1983 and that they were already significant exporters to New Zealand, South Africa and the Pacific (Lee 1993: 136-40). 


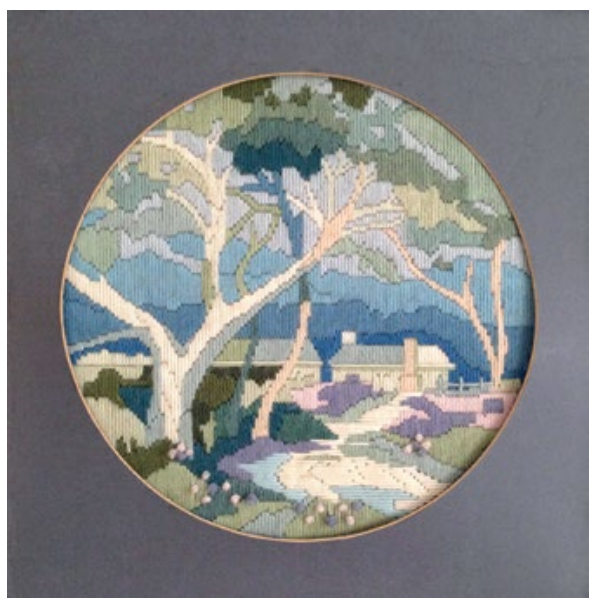

Figure 5. Maker unknown, Semco Long Stitch Originals series, title and kit no. unknown

Photo: Sera Waters

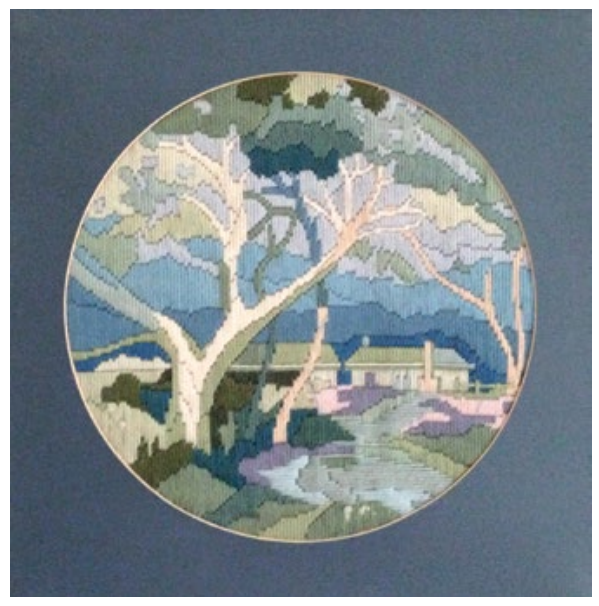

Figure 6. Maker unknown, Semco Long Stitch Originals series, title and kit no. unknown

Photo: Sera Waters

The series arrived in a period marked by the rise of women in the workforce (and a correlative decline in time for 'homemaking'), the waning place of embroidery within Australian schools, emerging stylistic shifts away from aesthetics of production, and the rise in availability and affordability of massproduced home items. This period, as surmised by Lee, marks a shift, not unnoticed by Semco, that Australian women were 'being educated to become consumers instead of producers of household necessities during this era in capitalism' (1993: 21). In contrast to the 'make-do' approach of Australian households and actively enabled by the Country Women's Association during pre-1950s times of economic hardship and straitened resources (Eagle 2001: 8), the Semco long stitches (which were not necessities) minimised production in favour of consumption. Emphasis thus shifted with this series from applying honed skills of needlework, to recreating a needlework-effect. The use of wool, I argue, indicates a nostalgia for the diminishing practice of handicrafts within the domestic setting and, with this loss, 'a rupture within an historical body of knowledge' (Burn 1993: 11). Embroidery, tapestry and needlework within the home have long been signifiers of feminised acts of making home; bringing together time, pride, comfort, love and centuries of knowledge passed down through generations. Even though the Semco long stitches exploit simplicity and swift execution, in benign imitation of more labour-intensive needlework forms, they are purposefully made within and for display in the home in material homage to needlework as a fading form of homemaking.

These long stitches also imitated painting in their similarity to paint-by-numbers kits, using wool instead of paint to create the effect of rippled skies, foliage and well-kept homes on fertile land. Examination of their design reveals their development from paintings: washes of painted colour have been translated 
into irregular wool shapes of shaded tones, and brush marks are inferred by the direction in which the wool is stitched (Figure 7). Like their painting equivalent, these long stitches were a kitsch and accessible pursuit 'sold as an artistic, pleasant and productive use of leisure time' (Knott 2013: 181).

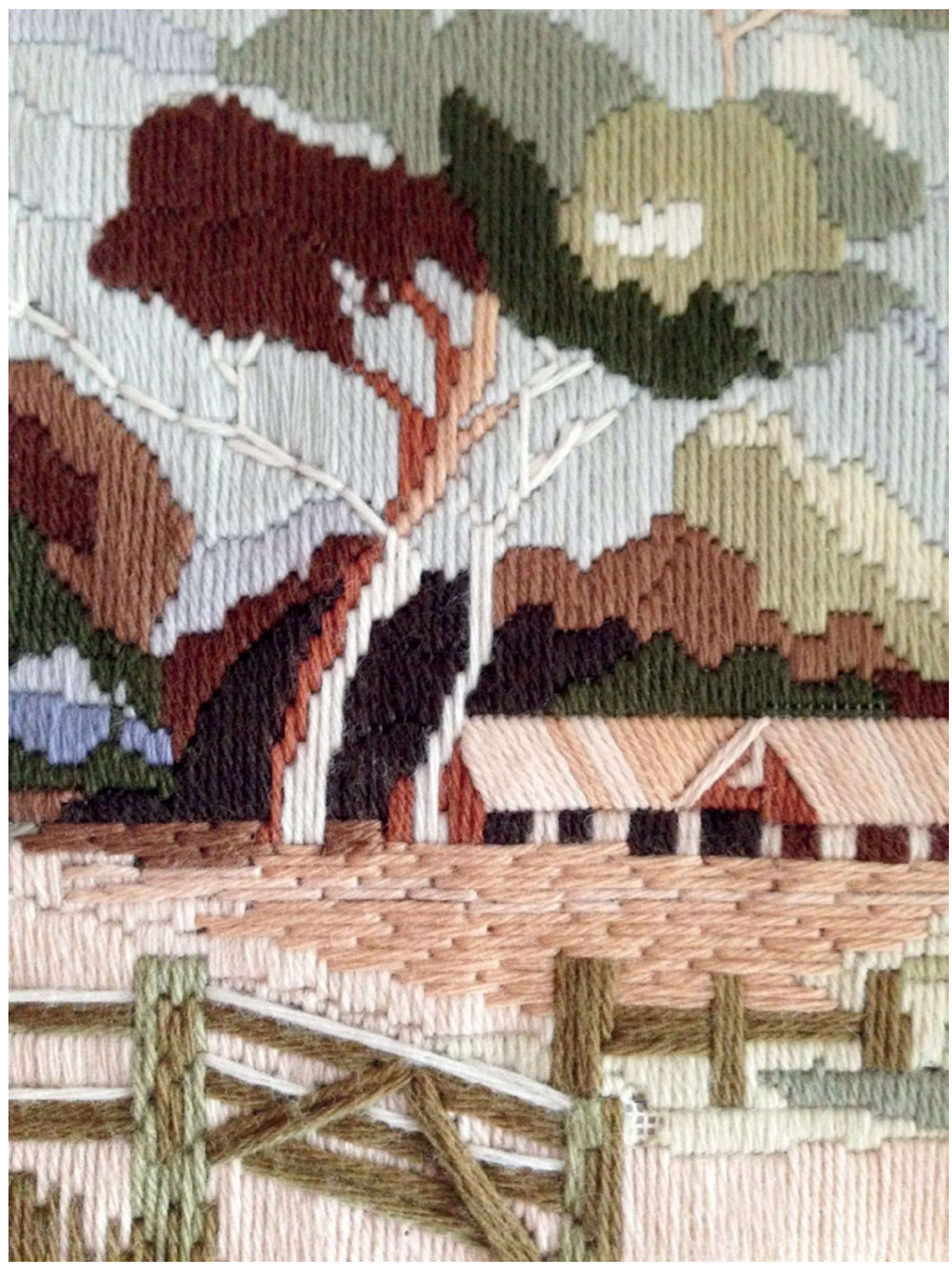

Figure 7. Maker unknown, Semco Long Stitch Originals series, title and kit no. unknown Photo: Sera Waters 
Semco's Long Stitch Originals series and other wool products were designed for display within the home. ${ }^{10}$ Following the release of the crewel series, general manager Robert McAdam noted a change in consumer desire when he proclaimed 'the trend is to decorative rather than utilitarian embroidery' (Dexter 1973). The long stitch kits, designed as wall hangings, operated as portals, not unlike reproduction landscape paintings; their main function was to enact looking and, while doing so, to privilege a selected and constructed view from the comfort of home. In line with their decorative and idyllic nature, art historian W.J.T. Mitchell, in response to Raymond Williams's remark that 'a working country is hardly ever a landscape', suggests that 'the invitation to look at a view is thus a suggestion to look at nothing-or more precisely, to look at looking itself-to engage in a kind of apperception of space as it unfolds itself in a particular place' (2002: viii). As representations of 'Australia' to be worked, then lived with and dwelled upon, the Long Stitch Originals series exerts a 'subtle power'11 and can be seen as Semco's 1980s version of the 'nostalgic view of a domestic idyll', once sought from Britain but now located in mythologised Australian landscapes.

Nostalgia, according to Svetlana Boym, is the 'desire ... to obliterate history and turn it into private or collective mythology' (2001: xv). The most overt form of nostalgia in these long stitches is their pictorial longing for an Australian past as expressed through idealised landscapes. From the 1970s onwards, Semco began to incorporate a range of overtly mainstream Australian motifs in their wool products, beginning with the celebrated (and highly reproduced) Heidelberg paintings. The crewel precursors to the Long Stitch Originals series were described as 'resembling a combination of [William] Dobell and [Russell] Drysdale', particularly with the pattern titled 'The outback pub' (Dexter 1973). This resemblance to Australian landscape paintings was carried on with the Long Stitch Originals series and, while the 'outback' was expanded to include some bush and possibly outer suburban scenes (such as 'The terrace', kit no. 3096), they were overwhelmingly pastoral. Amongst the winding paths, native foliage and open skies, is an ongoing presence of homemaking on a simultaneously national and domestic scale. In typically rural Australian settings, human industry melds with nature in scenes that feature various types of established housing, wooden palings, towering eucalypts, cottage gardens, tracks, grazing animals and, sometimes, a man working the land (never a woman). With titles such as 'Quiet morning', 'Sunny cottage', 'Summer solitude', 'Shearing time', 'The bullock wagon' or 'Afternoon reflections', a generalised picture emerges of an Arcadian Australia that is spacious, productive, and safe.

10 In the 1980s, Semco also released Long Stitch Innovations, a series celebrating seasonal imagery; kits aimed at children, such as the Fun Stitch series ('Long stitch' 1986); and kits employing other needlework techniques such as cross-stitch.

11 Mitchell notes that, given the chance, he would retitle his book to acknowledge that the power of landscapes 'is a relatively weak power compared to that of armies, police forces, governments and corporation [but] exerts a subtle power over people, eliciting a broad range of emotions and meanings that may be difficult to specify' (2002: vii). 
'Station sunset' (kit no. 3079, Figure 8), is just one example that presents the pastoral ideal in the extreme, which fits with Jeanette Hoorn's description of such landscapes as 'a frictionless space devoid of labour with an abundance of nature's gifts in a calm and leisurely setting' (2007: 9). Its soft pastel pinks, purples and olives are similar to the tones of Tom Roberts's painting 'Evening, when the quiet east flushes faintly at the sun's last look' (1887-88), which is described as 'capturing le moment crepusculaire, the stillness of dusk' (Lane 2008). This long stitch presents a moment of pause, with livestock, quietly feeding before a station, come to rest with the setting sun. Implicit in Roberts's distant view of pastoral land is that as '... a national picture ... its subtext is the claiming and clearing of the land' (Lane 2008). In contrast, the focus of 'Station sunset' falls upon the homestead, which blocks the horizon line. The viewer is positioned within fence lines that limit the view to one of domestic containment. Despite being an exterior view of a station, this image does not look out and, thus, continues to present an interior view of settled Australia.

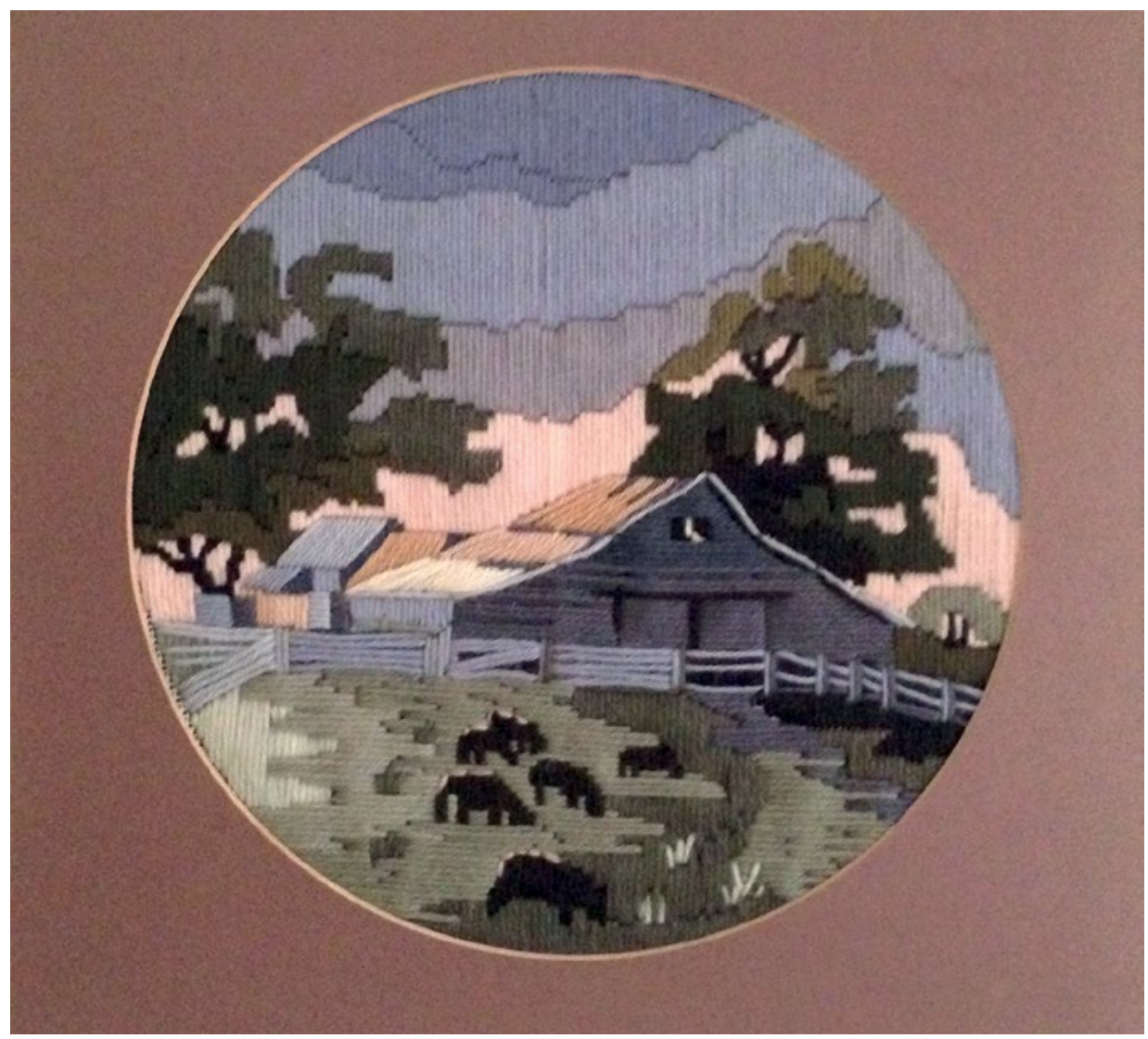

Figure 8. Maker unknown, Semco Long Stitch Originals series, 'Station sunset', kit no. 3079

Photo: Sera Waters 
Such visions of 'Australia', I suggest, borrow significantly from the ideals present in landscapes of the interwar period that lan Burn examined in his lecture 'A landscape is not something you look at but something you look through' (1993). Burn analysed within paintings, including Penleigh Boyd's Morning light (1922), Hans Heysen's White gums (1926) and Arthur Streeton's The land of the golden fleece (1926), the creation of a 'pastoral utopia', enacted by the 'artist's ability to abstract social significance from the real' (1993: 23). He claimed that it was 'through those social processes of idealisation and abstraction, a powerful rhetoric, a visual rhetoric, emerged'; a rhetoric that 'frames the landscape as a metaphor or symbol of nation' (1993: 23). The symbols put forth by 'pastoral utopias', and their uptake by media during the interwar period, were vehemently upheld and protected, according to Roslynn Haynes who claims that idealised images of Australia were one means to stimulate foreign economic investment (1998: 162). As a result, views of 'Australia' that resembled troubling actualities and could potentially suggest financially unstable realities (such as the severe 1920 drought recorded in film, photographs and disparaging commentary) were censored in international as well as Australian media (1998: 162). While levels of censorship wax and wane according to political and social climates, it is not surprising that idealised landscapes are a powerful form of national imagemaking in painting, photography, journalism and, for domestic audiences, even in wool long stitches half a century later.

Idealised landscapes often develop from a sense of threat. To seek to control the 'threats [and] ... forces we feel we cannot control' (Burn 1993: 23), we exclude them and, thus, interwar Australian landscapes were rendered as peaceful, pastoral and with 'no sense of the single moment':

The masculine ideals of the war were used to promote and validate a particular landscape of peace, an ideal of pastoral harmony, wealth and national potential. The new vision of the landscape found its embodiment in a 'pure' landscape icon, a gestalt which did not distract the eye with detail or narrative incident, in which one may encounter unnecessary references to contemporary life. Such an icon of pastoralism was offered for silent contemplation. (Burn 1993: 25)

In their quietness, this type of landscape becomes reverent, something to protect and which offers protection from outside forces. The interwar painters and, later, the long stitch designers in their quest for idyllic landscapes, adopted visual tactics such as abstraction, the creation of intimacy through a shallow pictorial space (Burn 1993: 22-23), and created the impression of timelessness through generalisation (or lack of specific details). 


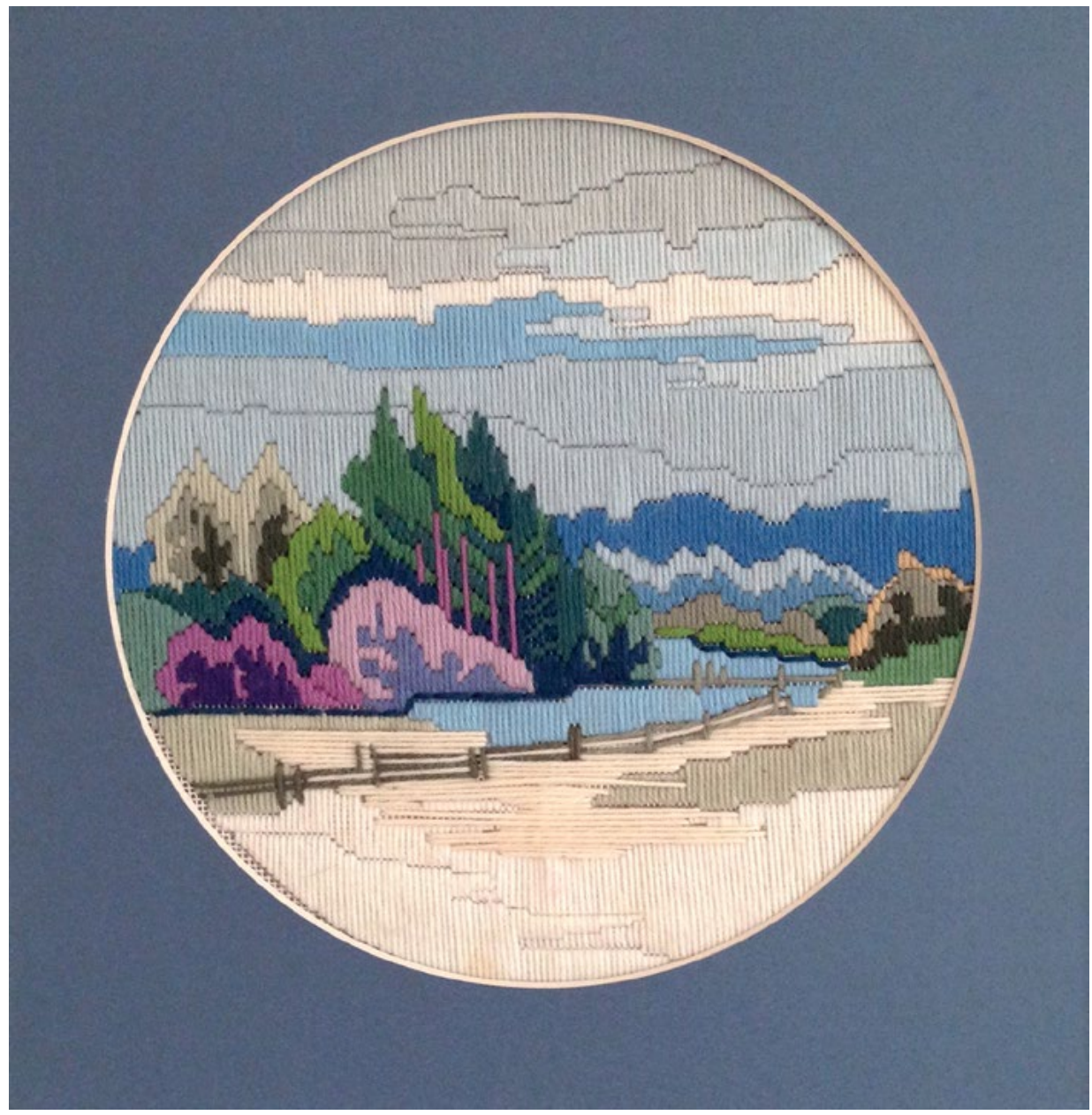

Figure 9. Maker unknown, Semco Long Stitch Originals series, 'Morning frost', kit no. 3080

Photo: Sera Waters

The passive power hiding in this visual language bears similarity to the ambiguity Homi K. Bhabha explores within discourses of nationalism (1990: 1-7). These ambiguities, as well as ambivalences, can be seen replicated in Semco's Long Stitch Originals series where they occupy, as Hannah Arendt so aptly describes, 'that curiously hybrid realm where private interests assume public significance' (cited in Bhabha 1990: 2). Part of this ambiguity arises from the fact that this Semco series is not being examined here as 'authored' works of art, and neither were they considered this way during their development. As Lee expresses: 'The designs seemed to be viewed by management as part of the process of production, rather than as works of art, as the designers could not put their signatures to their work' (1993: 136). The implications of this un-authoring, a generalising or blanketing approach, not only confirms their collective 
examination here as cultural and material productions, rather than as individual works of art, but speaks to the ambiguous space they occupy. Without 'author' or 'authority', these long stitches float across private and public desires to foster belonging, literally proffering nostalgic images of home, and appealing to the desire 'to rebuild the ideal home that lies at the core of many powerful ideologies of today' (Boym 2001: xvi).

Semco's process of absorbing and containing the individual designers and designs into one series of consumable products, mirrors the treatment given to the picturing of 'Australia' as nation. The destabilisation of 'author'from unknown designers to eventual makers-correlates to the non-specific depiction of 'Australia' dispersed at a mass level; a depiction of a place with no 'authority', a non-specific location that lacks local histories or lived experiences. In his book Reading the Country, Stephen Muecke takes up a 'theory of place' and explains the effects of the removal of specificity:

\begin{abstract}
... place introduces specificity and difference-new areas to be investigated within a larger whole. In Australia, the most commonly uttered place-names refer to large unities: 'Australia', 'Melbourne', 'The Northern Territory' and even 'The Kimberleys'. These unities are so large they become abstract and general, they evoke stereotyped and familiar responses which feed off ideologies like nationalism, 'stateism' or the urban/rural division. The study of specific, local places puts things more on the scale of everyday living. (cited by Lucy 1986: 88)
\end{abstract}

The names given to the places represented in these long stitches, such as 'bush' or 'outback', are sites that dwell in the national cultural imagination rather than in places with specific, local and layered histories. As spatial theorist Paul Carter surmises: 'As the colonist advances ... he wipes out every sign of difference, covering up the swerve of historical experience, reducing the land to a blankness' (cited in Rutherford and Holloway 2010: 7). This long stitch series not only takes its lead from late colonial landscape traditions and colonisation itself, but the images are materially blank; up close, the distanced woollen landscapes dissolve into fuzzy strands that carry no specificity, no stories and, not surprisingly, no acknowledgement of the spiritual connection to country of Indigenous Australians.

As well as invoking generalisations and, with them, stereotypes around nation, these long stitches also take up the landscape strategy of distance, in this case decorative distance. As W.J.T. Mitchell explains:

The landscape imperative is a kind of mandate to withdraw, to draw out by drawing back from a site. If a landscape, as we say, 'draws us in' with its seductive beauty, this movement is inseparable from a retreat to a broader, safer perspective, an aestheticizing distance, a kind of resistance to whatever practical or moral claim the scene might make on us. (2002: viii) 
Being drawn in and back simultaneously into a 'safe' perspective encourages a viewer to imaginatively place themselves within these non-specific scenes. By contrast, Susan Best, in a review of the exhibition Photography and place: Australian landscape photography 1970 until now, highlights the shared approach of artists viewing the Australian landscape from a postcolonial perspective; 'that none of them enable or suggest easy entry into the depicted landscape' (2011: 34). Unlike the long stitches, whose domesticated landscapes activate a desire to become absorbed into an idealised space, their photographs do not present accommodating landscapes (Best 2011: 34).

The patterning employed in the Semco landscape designs, not unlike mapping, has overridden specific stories of Australia, Indigenous and non-Indigenous, men and women, and the historical patterns of this land, with demarcated (fenced) blocked and blank areas of wool. Considering patterning and patterns as a visual form of marking out territory, the lines of these long stitch patterns chart predetermined static scenes that inhibit the potential of finding new and nuanced, complex and relational territories like those expressed in Ross Gibson's concept of 'changescapes' (2005). The patterns of these long stitches, like the patterns performed in picturing 'nation', are boundaries that restrict an individual experience to predetermined and generalised parameters. The extension of patterns into sociocultural territory correlates with patterns of 'seeing' Australia that omit complexity, diversity and specificity, in favour of an ideal. A prevalent pattern in Australian history is viewing the space of feminised domesticity as passive. When colonised landscape patterns of the outside are brought inside, opportunities to reflect individual experiences are restricted. A reading of the Semco Long Stitch Originals series that cannot be ignored is the continuation of outdated gendered roles of British exploration, colonisation and domestication; a land, mapped and tamed by men, is brought into the home to women for the final stages of taming.

Through the frame of Semco's popular Long Stitch Originals series can be seen Australian expressions of cultural containment and denial that were also taken up by a raft of other mass-produced Australian cultural products throughout the 1970s and 1980s. In the lead up to the bicentenary celebrations of 1988 , they took the form of a nostalgic and outmoded landscape language, a defence mechanism that protected the now more flimsy concepts of 'home' and 'nation'. The designers appointed by Semco were simply responding to a popular demand for non-specific and non-contested views of Australian landscape, taken up so readily in this period. In retrospect, however, '[t]he insidious power of signifying practices, indeed, is that they carry their "determined sets of meanings" with them, regardless of a producer's intention' (Lucy 1986: 90). This series, like much popular culture of the time, can be read today as a visual manifestation of a refusal to acknowledge the postcolonial contestation of land ownership, which, for many artists, as Susan Best observes within 1970s photography, meant 'a straightforward depiction of the land lost force and interest' (2011: 34). While artists began to shift their view, looking down to acknowledge their 
footsteps and their imprint on this land, the mass Australian imagination, seen here through Semco's long stitches, continued to be drawn in by a horizontal and idealised view across a land.

In the 1980s, the stereotyped Australian pastoral landscape of bright light and gum trees captivated the mainstream in numerous forms. Television series, playing in the heart of the home (perhaps with Semco long stitches hung nearby), such as $A$ country practice, The flying doctors and, earlier, Skippy, appealed with their idealised rural Australianness. More tellingly was the 1986 success of the Art Gallery of New South Wales's Golden summers: Heidelberg and beyond, a blockbuster exhibition of Australian Impressionist paintings that received record attendances and travelled from Sydney to Melbourne, Adelaide and Perth. According to Anne-Marie Willis, many of the visitors 'were visiting familiar works-works known through multiple encounters with reproduction over many years' (1993: 86). Though it is impossible to measure the effect 'nation' landscapes have had-a passive force that W.J.T. Mitchell describes as an 'indeterminacy of affect' (2002: vii)-it is apparent in this drive to visit familiar works, to invoke nostalgia, or to long stitch stereotypical scenes, that the myths of Australian landscapes endure and are kept active via reproduction. Willis argued that the exhibition, which "claimed "de-mythologisation" became re-mythologisation ... [as] mythologies for the present are manufactured by claiming the authority of the earlier ones' (1993: 88). This, too, can be said for the uptake of Australian mythologies in popular cultural products such as Semco's Long Stitch Originals series and fits with Willis's suggestion that the 'operational strategy of national imagery is one of recycling, remanufacture and relocation' (1993: 88).

Though I have aligned this series with an idealisation seen in interwar landscapes, I also suggest that many borrow from the nation-making paintings associated with Australian Impressionism. In the woolly strands of sky-blue, dusty or late afternoon-an idea of Australian light is expressed, influenced by the exemplary, sensitive and extensive explorations of Arthur Streeton and, later, Hans Heysen. As imitations though, these long stitches fit Tim Bonyhady's descriptions of the raft of 'hackneyed' inferior versions that 'reduc[e] ... the landscape to a stereotype of bright sunshine and scattered gum trees' (1985: 156). Bernard Smith called this a 'national vice' (cited in Bonyhady 1985: 156). All the same, in the 1980s, clichéd and nostalgic views of Australia were popular and prevalent.

While nostalgia, according to Svetlana Boym, is often referred to dismissively (2001: xiv), an examination of nostalgia and its mass invocation in 1980s Australia is insightful. It could be argued that the 1980 s were not dissimilar to the period of and between the great wars in that a 'threat' to 'home' was perceived, this time arising from inside, rather than outside. In response to the challenges in facing our colonial history of settling, came the long stitches, amongst a sea of other cultural products, using myth and national nostalgia as a means to conjure a clichéd expression of 'belonging'. The resulting pastoral landscapes removed 
all threats and challenges, and, as such, can be read as visual recreations and assertions of a past that never happened, one that erases the complex and mourns 'the impossibility of mythical return, for the loss of an enchanted world with clear borders and values' (Boym 2001: 8). To create these scenes, distance was essential. And, just as the interwar landscapes employed the expansive perspectives of recently returned soldiers, the long stitched landscapes took an intentional outside view. As Boym explains, 'national awareness comes from outside .... it is the romantic traveler who sees from a distance the wholeness of the vanishing world' (2001: 12). Boym describes two forms of nostalgia: restorative and reflective. Restorative nostalgia 'protects the absolute truth, while reflective nostalgia calls it into doubt' (2001: xvii). The mass-dispersed Semco long stitches, as futile attempts to still a shifting 'home', fit with the restorative form of nostalgia, problematically presenting through the landscape the 'truth' of a 'national memory that is based on a single plot of national identity' (Boym 2001: xviii).

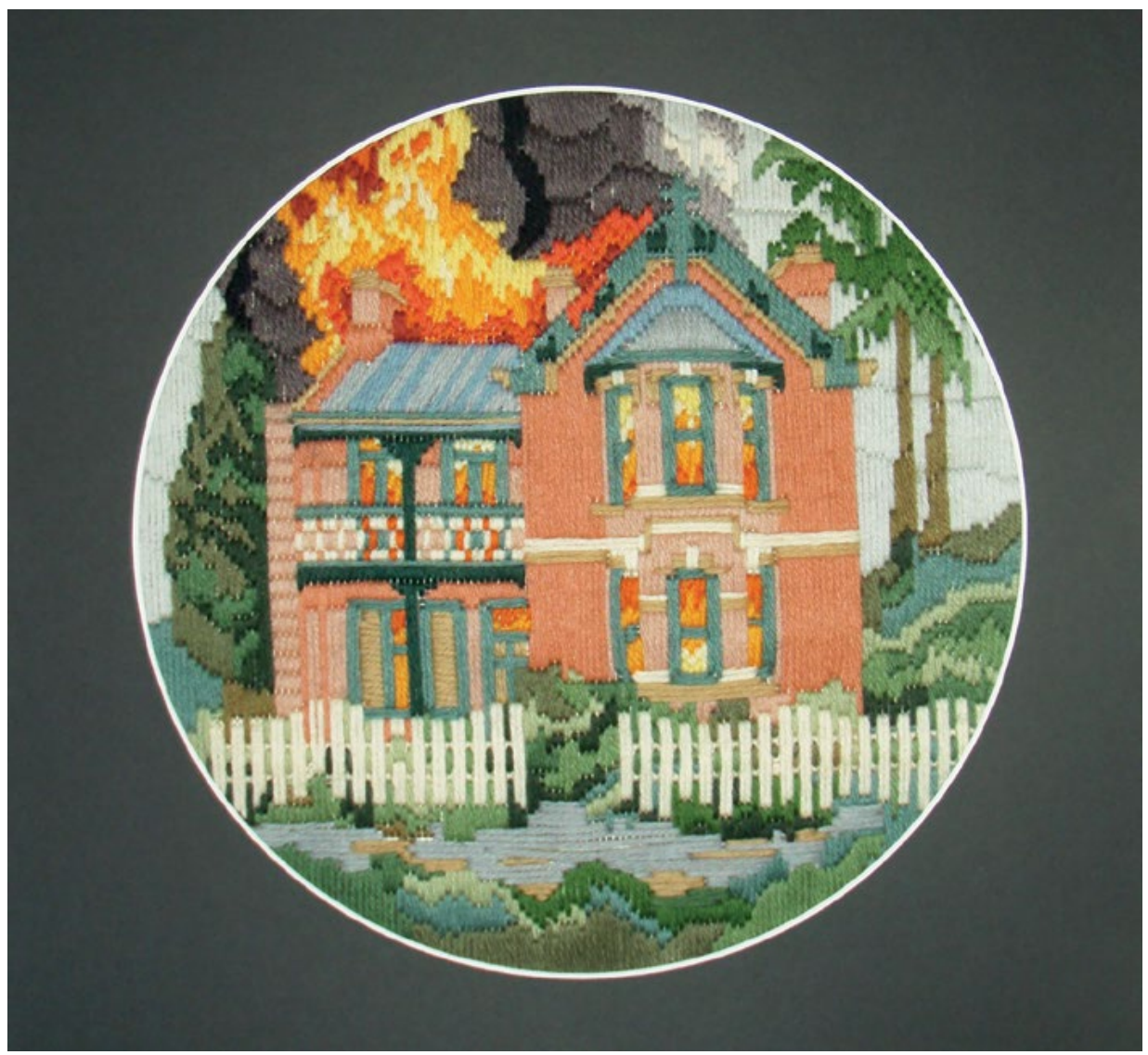

Figure 10. Sera Waters, Paradise tampering: The house fire, 2010, Semco Long Stitch Originals series, 'The manor', kit no. 3095, wool

Photo: Sera Waters 
Thirty years on from their release, the framed landscapes of the Semco Long Stitch Originals series appear to occupy more second-hand and opportunity shops than homes. Their visual rhetoric is outmoded and their domestic place has been filled with new interpretations of our local and global lives. Juliette Peers notes a similar dismissal of works by the Australian Impressionists, noticing 'the Heidelberg School no longer seems to quite matter ... in the manner that it mattered throughout the 1990s and for extended periods in the mid- to late twentieth century' (2005: 182). Like the national mythologising that is linked to the painting of the Heidelberg School, the sentimentalised landscapes of the Semco long stitches have moved away from current concerns; their particular view of long stitched 'Australia' having been eroded, notably by a 'decline in the importance of agricultural industries' (Elder 2007: 74) and changes wrought by native title legislation that continue to destabilise many national myths. Decades on, these material and cultural artefacts are no longer fashionable as decoration and have, instead, 'become remembrances of things and times past' (Lee 1993: 61).

It is notable today that these kits are underappreciated and, as far as my explorations discovered, are not part of institutional collections-despite the fact that earlier and finer Semco embroideries made from patterns and kits are being collected by institutions. ${ }^{12}$ As this essay has argued, through examining their patterns of nostalgia, decorativeness, consumption and imitation of idealised Australian landscapes, the Semco Long Stitch Originals series houses an expression, popular in the 1970s and 1980s, that disavows the realities of a colonial past. As well, when seen as products positioned in a long line of Semco manufacturing and development driven by consumer demand, these long stitches reflect, from a conservative perspective, the slow and ambiguous shift in concepts of Australian domesticity. Rather than leaving no gaps, as technically required of long stitch, by allowing gaps (and indeed acknowledging this series as filling-or rather forming - a gap in our understanding of this period) these long stitches can be repositioned as ambiguous human expressions of 'reflective nostalgia [which] dwells on the ambivalences of human longing and belonging and does not shy away from the contradictions of modernity' (Boym 2001: $x$ viii). If we continue to unpick this series, and reconsider them today, noting the specificity and exclusions they sought to contain, they compel us to find, in the words of Paul Carter, '... a poetics of situations, occasions or unfinished tracks rather than complete outlines' (cited in Rutherford and Holloway 2010: 9).

Sera Waters is an Adelaide based artist and arts writer. She is Head of Art History and Theory at Adelaide Central School of Art and is currently undertaking postdoctoral research at the University of South Australia. Her PhD title is 'Settling ghosts: A visual arts enquiry into repetitious acts of making home in settler Australia'. 


\section{References}

Best, S., 2011, 'Landscape after land rights, after conceptual art: Photography and place', Eyeline, no. 75, pp. 33-37.

Bhabha, H.K. (ed.), 1990, Nation and Narration, Oxon: Routledge.

Bogle, M., 1998, Design in Australia 1880-1970, Sydney: Craftsman House.

Bonyhady, T., 1985, Images in Opposition: Australian Landscape Painting 18011890, Melbourne: Oxford University Press.

Boym, S., 2001, The Future of Nostalgia, New York: Basic Books.

'Brandcorp - Innovative world class brands', 2009, Aussie Crafts, viewed 10 May 2014, www.aussiecrafts.com.au/crafts/links/detail/734.

Burn, I., 1993, 'A landscape is not something you look at but something you look through', Australian Journal of Art, vol. 12, 1994-95, pp. 21-30.

- 1 1984, 'The 1960s: Crisis and aftermath', in Paul Taylor (ed.), Anything Goes: Art in Australia 1970-1980, Melbourne: Art \& Text, pp. 9-23.

'Cooks' cottage', 2013, City of Melbourne, viewed 20 Jun 2014, www. thatsmelbourne.com.au/Placestogo/MelbourneLandmarks/Historic/ Pages/4450.aspx\#contact

Daly Goggin, M., 2002, 'An essamplaire essai on the rhetoricity of needlework sampler-making: A contribution to the theorizing and historicizing rhetorical praxis', Rhetoric Review, vol. 21, no. 4, pp. 309-38.

Dexter, N., 1973, ‘From worn doyley to decor’, Age (Melbourne), 6 Aug, p. 14.

Eagle, M., 2001, 'Contemporary art, women, the CWA and DJ's: A fresh look at Australian art history, the "principles of art", and creativity', in Vivonne Thwaites (ed.), Home is Where the Heart is, exhibition catalogue, Adelaide: Country Arts SA, pp. 6-11.

Elder, C., 2007, Being Australian: Narratives of National Identity, Sydney: Allen \& Unwin.

Fletcher, M., 1989, Needlework in Australia: A History of the Development of Embroidery, Melbourne: Oxford University Press.

Gamble, L., 2013, 'Semco of Black Rock', City of Kingston Historical Website, viewed 28 January 2015, localhistory.kingston.vic.gov.au/htm/article/579.htm. 
Gibson, R., 2005, 'Changescapes', 2005 IDEA Journal, pp. 195-206, viewed 1 May 2014, idea-edu.com/wp-content/uploads/2013/01/2005_IDEA_Journal. pdf.

Haynes, R.D., 1998, Seeking the Centre: The Australian Desert in Literature, Art and Film, Cambridge University Press.

Hoorn, J., 2007, Australian Pastoral: The Making of a White Landscape, Fremantle Press.

Isaacs, J., 1987, The Gentle Arts: 200 Years of Australian Women's Domestic \& Decorative Arts, Sydney: Lansdowne Publishing.

Knott, S., 2013, 'A theory of the paint-by-number surface', in Glenn Adamson and Victoria Kelley (eds), Surface Tensions: Surface, Finish and the Meaning of Objects, Manchester University Press, pp. 181-92.

Lane, T., 2008, 'Turner to Monet: The triumph of landscape education resource: Tom Roberts: "Evening, when the quiet east flushes faintly at the sun's last look" (1887-88)', National Gallery of Australia, viewed 1 March 2015, nga. gov.au/exhibition/turnertomonet/Detail.cfm?IRN=165581\&BioArtistIRN=245 04\&Audio=16k\&ViewID=1\&MnulD=1.

Lee, R.L., 1993, 'Our fingers were never idle: Women and domestic craft in the Geelong region 1900-1960', Masters thesis, Deakin University, viewed 2 April 2014, dro.deakin.edu.au/eserv/DU:30023336/lee-ourfingerswere-1993.pdf.

'Long stitch means a fast finish', 1986, Age (Melbourne), 20 March, p. 29.

Lucy, N., 1986, 'Review of Reading The Country: Introduction to Nomadology, Krim Benterrak, Stephen Muecke, and Paddy Roe [with Ray Keogh, Butcher Joe, and E.M. Lohe], Fremantle Arts Centre Press', Westerley, no. 4, viewed 20 May 2014, westerlymag.com.au/wp-content/uploads/2013/03/ reviews1.pdf.

Mitchell, W.J.T. (ed.), 2002, Landscape and Power, 2nd edn, London: The University of Chicago Press.

Parker, R., 1984, The Subversive Stitch: Embroidery and the making of the feminine, London: The Women's Press.

Peers, J., 2005, 'Heidelberg School in a new millennium', in Rex Butler (ed.), Radical Revisionism: An Anthology of Writings on Australian Art, Brisbane: Institute of Modern Art, pp. 182-99.

Rutherford, J. and Holloway, B. (eds), 2010, Halfway House: The Poetics of Australian Spaces, Crawley: The University of Western Australia Publishing.

'Tapestry wool', 1979, Canberra Times, Monday 16 July, p. 12. 
Wilkins, R. (ed.), 2014, 'Families, incomes and jobs, volume 9: A statistical report on waves 1 to 11 of the Household, Income and Labour Dynamics in Australia (HILDA) Survey', Melbourne Institute of Applied Economic and Social Research, University of Melbourne, viewed 20 June 2014, www.melbourneinstitute.com/ downloads/hilda/Stat_Report/statreport-v9-2014.pdf.

Willis, A., 1993, 'Nation as landscape', in Illusions of Identity, Sydney: Hale \& Iremonger, pp. 61-92. 
This text is taken from Craft + Design Enquiry, Issue 7, 2015, edited by Kay Lawrence, published 2015 by ANU Press, The Australian National University, Canberra, Australia. 